\title{
Corrosion stratifications on glass jewellery excavated beneath the market square in Kraków, Poland
}

\author{
Dominika Zabiegaj ${ }^{1}$, Barbara Szala², Elżbieta Greiner-Wronowa ${ }^{3}$ \\ ${ }^{1}$ CNR, Institute for Energetics and Interphases; Genova, Italy \\ ${ }^{2}$ AGH University of Science and Technology, Faculty of Geology, Geophysics and Environmental Protection; \\ al. Mickiewicza 30, 30-059 Krakow, Poland; e-mail: basia.szala@gmail.com \\ ${ }^{3}$ AGH University of Science and Technology, Faculty of Materials Science and Ceramics; \\ al. Mickiewicza 30,30-059 Krakow, Poland, e-mail: egrwrona@agh.edu.pl
}

(C) 2014 Authors. This is an open access publication, which can be used, distributed and reproduced in any medium according to the Creative Commons CC-BY 4.0 License requiring that the original work has been properly cited.

Received: 9 September 2013; accepted: 26 July 2014

\begin{abstract}
Glass has been one of the materials selected for its decorative purposes since early mankind. Its production was complex and varied all around the world, considering the sources of local materials used for its production as well technological knowledge about the manufacturing process. The aim of this work is to put some light on glass jewelry unearthed during the archeological excavations at the Main Market Square in Kraków, and to increase the importance of a stratifications investigation of ancient subjects by induced corrosion, using glass sensors.

The collected data helps to determinate the definitive condition of a historical object. This data will also help to establish the chemical nature of the corrosion products and the altered glass and metal surfaces. Moreover, the ring presented in this work can be considered to be from a small group of fine medieval jewelry corresponding to the upper class of the population, such as the nobility or wealthy merchants. Such individuals dealt with the exchange of goods with foreign countries. Because of a very limited amount of analytical material, only nondestructive analysis: scanning electron microscopy (SEM) and energy dispersive X-ray spectroscopy (EDXS), X-ray diffraction (XRD), X-ray fluorescence spectrometry (XRF), glass sensors were applied. The glass and metal have been tested separately.
\end{abstract}

Keywords: induced corrosion, glass corrosion, metal corrosion, glass jewelry, glass sensor

\section{INTRODUCTION}

Glass is one of the oldest man-made substances ever produced. Its production began even before the beginning of human civilisation, being a natural product. So called natural glass is produced whenever glass-forming rocks melt under high temperatures and solidify quickly. This happens when volcanoes erupt (obsidian), when lightning strikes into quartziferous sand (fulgurites) or when meteorites hit the surface of the earth (tektites). Such naturally occurring glass, especially the volcanic glass obsidian, has been used by many Stone Age societies across the globe for the production of sharp cutting tools or weapons (arrowheads, spearheads, knives) and due to its limited sourcing areas, was extensively traded. Artificial glass, on the other hand, came only when civilizations began to form (Pfaender 1996, Lierke 2009).

Although it is not known precisely when glass was first made artificially by man, the oldest recovered artifacts (greenish glass beads) date back to $3500 \mathrm{BC}$. It is thought that glass-making originated in Egypt and Mesopotamia, but developed later and independently in China, Greece and 
the Northern Tyrol. Ancient glass manufacture is believed to be linked to the production of ceramics or bronze, where it could have originated as a by-product.

The indigenous development of glass technology in South Asia may have begun in 1730 BC. Evidence of this culture includes a red-brown glass bead along with a hoard of beads dating to that period, making it the earliest attested glass from Indus Valley locations. Following ancient scripts written by Roman historian Pliny (AD 23-79), glass was discovered by Phoenician merchants transporting stone in the region of Syria almost 5000 BC. He says that merchants after landing, rested cooking pots on blocks of nitrate, with the intense heat of the fire placed on them. The blocks melted and mixed with the sand of the beach, forming an opaque liquid, accidentally. This story is more a reflection of Roman experience with glass production, nevertheless, the white silica sand from this area was used in the production of glass within the Roman Empire due to its low impurity levels.

The sophisticated technology needed to sustain glass manufacture derives from a variety of allied material technologies, predominantly ceramic and metal. There are needed to provide heat sources, tools, furnaces and material science, making its production really complex. All of those variables need to pre-date the use of glass within a society (Pfander 1996, Fuxi 2009).

In ancient times the most noteworthy limitation for glass fabrication was keeping the material chemically clean and homogeneous. This caused many technological problems and continuous modifications in the glass matrix. Furthermore, glass was a synthetic. This in itself was a sophisticated concept for a culture that was used to use materials that were already in existence: wood, bone, and stone or metal and clay (Lierke 2009). Glass in contrast, was the result of combining a mixture through heat. That is why all recipes of its fabrication have been kept in darkness for many centuries, and it is also why produced glass was seen to be a very desirable and prestigious product. Glass was seen as a material that could be made to imitate semi-precious stones, being accorded a status equal to that of the precious materials it imitated and thus, increased the social position of its owner.

Archeological evidence suggests that the first objects in which glass was used in their production were beads, plaques, inlays, and eventually small vessels. Glass jewellery such as rings, bead bracelets and necklaces became the most favourite decorations worn mostly by women but later, very often by men (Olczak \& Jasiewiczowa 1963, Dekowna 1980). There was a wide array of techniques used by middle age artisans to give the glass its form, to connect it with other materials or even to give it a different colour, from using the inherent colour to form the impurity of glass materials or by adding colourants such as cooper or silver (Theophilus 1880).

During recent archeological excavations performed beneath the Market Square in Kraków, a large amount of rings were found, giving great knowledge into developed glass manufacture and putting some light on the international goods exchange and the life of the elite class in the medieval town (WAWEL 1000-2000). A few from this collection include a group of metallic rings mounting glass beads. The typology of the ring taken into account in this study is chronologically and geographically placed in Slavic Early Medieval Age, typically found in graves or settlements (Eggert 2010, Zabiegaj 2010, Greiner-Wronowa 2013). It is worth to note that glass rings were from a very small group of jewelry, quantitatively not recognizable across Slavic regions, while metal rings were and still are quite common if not universal across Europe (Sulimirski 1943, Stawiarska 1984). According to archaeological evidence, the largest accumulation of such rings was observed in Poland, especially in Kraków, which was one of the main European trade centers (Biezborodow 1956, Olczak 1959, Shelby 2005, Lierke 2009). That is why the presented samples have a very significant meaning. Moreover, the different origins of samples as well as the stratifications observed, found in different soil layers, improve the city environment changes for hundreds of years. In spite of that it can tell us how the local microclimate has affected the degradation of the analyzed rings, developing different corrosion processes.

In the case of research on glass and taking into account the historical character/value of the materials to be analyzed, it is absolutely necessary to employ only those methods of analysis which do not require addtional sample preparation. That is why close collaboration between technologists and conservators is necessary. To define the 
glass-object stage, we have to cooperate with conservators in order to get more information about the previous storage and exposition conditions (Greiner-Wronowa 2005, Shelby 2005).

Nowadays, a wide spectrum of physical and chemical methods exist which help to determinate the corrosion products deposited on the material surface - even the chemical composition of the material from which the relics had been made. But a major problem is the amount and size of the original object used in research as in most cases, there is not enough to perform the necessary range of tests (Greiner-Wronowa 2005). Due to these limitations, a "glass sensor method" was developed and subsequently implemented. This method allows for the preparation of a glass sensor which replicates original historical objects with the same chemical composition and production attributes. The use of replicas of the original glass allows the user to perform an infinite number of tests without restriction (Greiner-Wronowa 2010).

The glass sensors samples were subjected to induced corrosion processes. The glass sensor used in this research was created based on the chemical composition of an eighteenth-century glass beaker. This sensor has the same chemical composition as an original antique glass with comparable chemical and physical properties, as well as similar reactive qualities. Selected corrosive agents (acid, water, etc.) were chosen on the basis of studies of the local environment of the glass-metal object. The corrosion processes induced on the glass sensor took only a few weeks. The sensor can be subjected to a plethora of tests and the results reflect the processes occurring within the original place of storage. Stratifications that have arisen on the surface of glass sensors represent the corrosion products on real objects. It is important to diagnose the impact of the environment on the condition of original historical artifacts as deposits and corrosion layers on the surface of the material can be a catalyst for further deterioration.

\section{MATERIALS AND METHODS}

Due to the historical value of the ring the investigation was performed with limited micro invasive sampling to perform the investigation on a cross section by scanning electron microscopy. It was done according to the conservation agreement. Moreover, the reduced size of the objects allowed the direct investigation of them by Scanning Electron Microscopy connected with Energy Dispersive X-Ray Spectroscopy (SEM-EDXS). $\mathrm{X}$-Ray Fluorescence spectroscopy (XRF) and X-Ray Diffraction (XRD) were additionally used to characterize the products causing alteration (Andrusieczko 1972, Kubiak \& Gołaś red. 2005).

Considering that the chemical stability of glass depends on many parameters, it is worth to mention that the connection of two or more materials to build a single object provokes an increase in the system complexity that alters some important aspects such as chemical and mechanical durability.
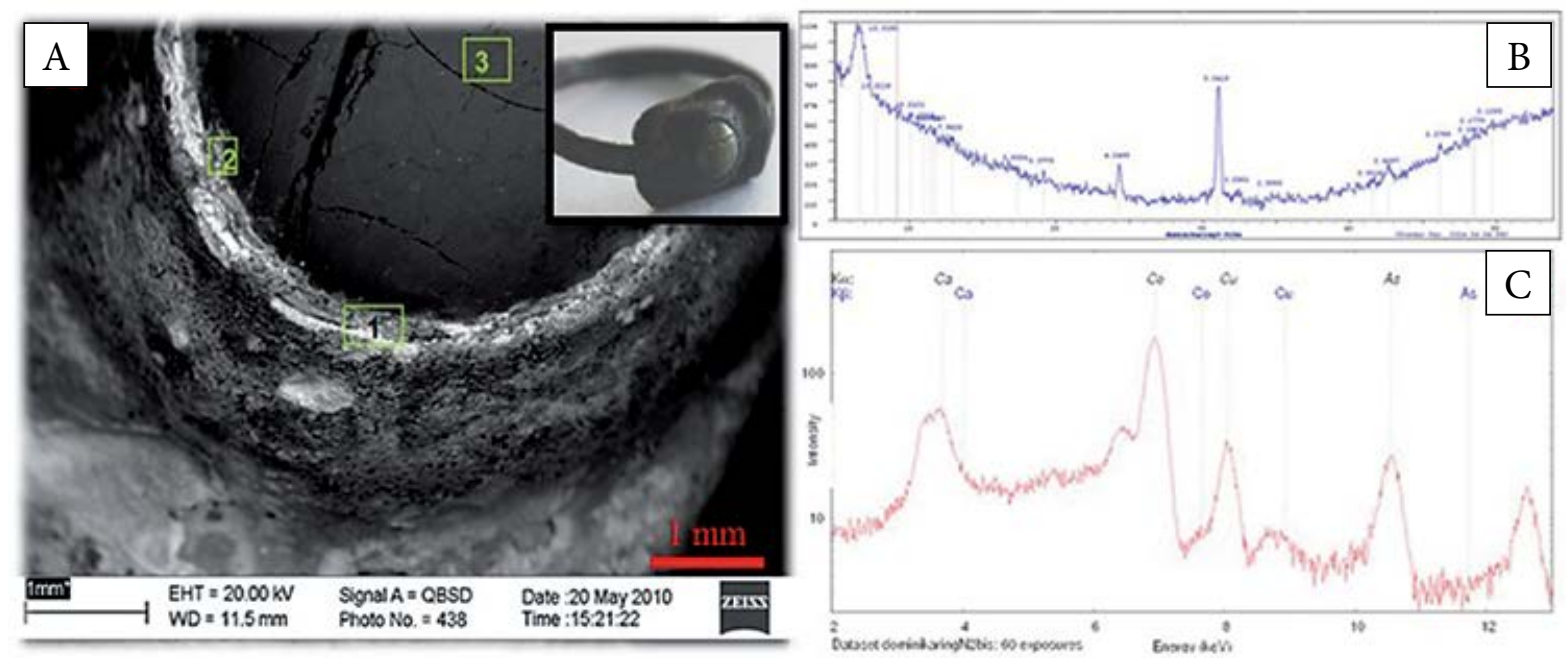

Fig. 1. Analyses of the ring's crown: SEM micrograph of the glass bead and glass-metal joint pathology (A); XRD (B) and XRF (C) analyses of dispersed corrosion products from the glass-metal interface 
In addition to this, the mutual interaction between the different materials might be also affected by its reactivity, like in the presented ring. For this purpose, before to study on the alterations occurring at the glass-metal interface, it is necessary to consider each single material separately (Greiner-Wronowa 2013).

Analyses were carried out on three significant areas of the presented ring, for a glass pearl (Fig. 1A) and for a metal band: on the corroded band surface (Fig. 2A); on the altered layers of corrosion products of the metal band (Fig. 2B); and on the un-corroded alloy of the ring, after grinding (Fig. 2C).

The last important area where observations were focused on was the glass-metal connection. For this purpose, the white solid clay placed between the glass eye and ring's crown has been taken and dispersed for further analyses by XRD and XRF. A portable XRD apparatus (TERRAC) that works on powders, allows a fast collection of spectra in the angle range between $5^{\circ}$ and $55^{\circ}$ using CoKa wavelength. The excitement of powders generates a fluorescent signal that is collected for qualitative analyses (Fig. 1C). The latter confirmed the presence of $\mathrm{Cu}$, As, and $\mathrm{Ca}$ while $\mathrm{Co}$ is due to the contribution of the X-ray source.

To improve the relevance of stratifications study of ancient subjects by induced corrosion, glass sensors were used to characterize the alteration products of the eighteenth century glass beaker (Greiner-Wronowa 2010). This sensor has the same chemical composition (Tab. 1) as an original antique glass with comparable chemical and physical properties, as well as similar reactive qualities. Glass with high alkali content
$\left(\mathrm{Na}_{2} \mathrm{O}+\mathrm{K}_{2} \mathrm{O}=15.22 \%\right.$ wt. $)$, with the addition of lead oxide is technically soft and called technological long glass. The prepared glass sensor was connected to the copper band and immersed in a $0.01 \mathrm{M}$ solution of hydrogen chloride $(\mathrm{HCl})$.

\section{Table 1}

The oxide composition of glass samples sensors [wt. \%] of the eighteenth century ancient glass subject. The glass samples were connected to the metal and subjected to induced corrosion

\begin{tabular}{|c|c|c|c|}
\hline $\begin{array}{c}\text { Oxide } \\
\text { composition }\end{array}$ & wt \% & $\begin{array}{c}\text { Oxide } \\
\text { composition }\end{array}$ & wt \% \\
\hline $\mathrm{SiO}_{2}$ & 73.94 & $\mathrm{Na}_{2} \mathrm{O}$ & 0.84 \\
\hline $\mathrm{CaO}$ & 9.26 & $\mathrm{BaO}$ & 0.14 \\
\hline $\mathrm{K}_{2} \mathrm{O}$ & 14.38 & $\mathrm{MgO}$ & 0.59 \\
\hline $\mathrm{PbO}$ & 0.066 & $\mathrm{Al}_{2} \mathrm{O}_{3}$ & 0.065 \\
\hline $\mathrm{MnO}$ & 0.096 & $\mathrm{~B}_{2} \mathrm{O}_{3}$ & 0.64 \\
\hline $\mathrm{Fe}_{2} \mathrm{O}_{3}$ & 0.056 & - & - \\
\hline
\end{tabular}

The reconstructed material was subjected to corrosion induced over a period of 20 weeks. To accelerate the corrosion of the sample, solutions were periodically subjected to an elevated temperature. Every other week, after 168 hours, they were placed in an elevated temperature of $40^{\circ} \mathrm{C}$. Throughout the duration of inducing corrosion on the samples, macroscopic observations were made and changes in weight were registered. After observing the appearance of corrosion products and the structural changes of samples, detailed studies were carried out at the University of Genoa. SEM/EDS was performed with a scanning
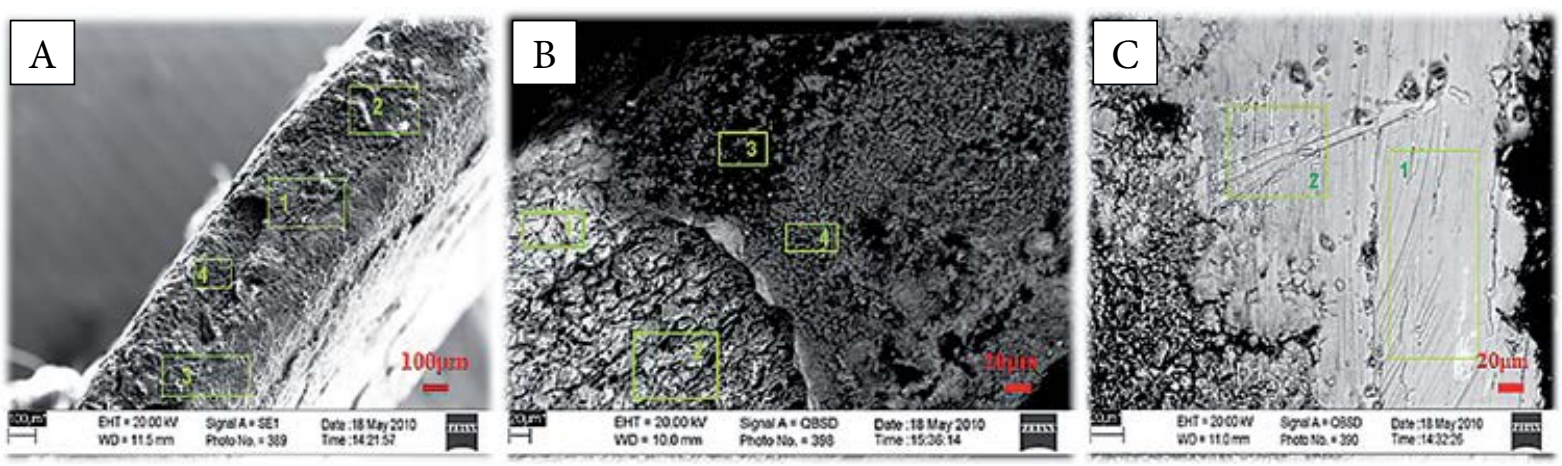

Fig. 2. SEM micrographs of the metal parts of the ring: A) corroded metal band; B) alterated layers of corrosion products of the metal band; C) the uncorroded alloy of the ring, after grinding 
electron microscope, Carl Zeiss AG-EVO 40 Series and atomic emission spectroscopy - for identifying the solution (ICP-MS DRCII by Perkin-Elmer). In order to determine the phase composition of corrosion products, Raman spectroscopy was performed using a Leica Renishow DMLM spectrometer.

\section{RESULTS AND DISCUSSION}

The ring which is the subject of this study includes a metallic band and a blind glass bead (called "eye") mounted in a metallic "crown" (Fig. 1A). The entire surface of the ring as well as the cross sections are severely affected by corrosion. The corners and the edges show numerous deformations. In particular, the part where tiny metallic sheets are holding the glass bead in the crown, the corrosion produced several holes. Moreover, the glass itself has been damaged and shows many scratches. Especially on the most representative area of the bead where a deep elongated crater is visible. Because of stratifications on the glass surface it is almost impossible to define its original color. In order to investigate the external layers of corrosion, several areas of the surface were studied.

For the first set up of SEM observation, the metal part of the ring that was not in contact with the glass part was chosen (Fig. 2A). The obtained EDS data revealed copper and zinc as the main metallic elements (followed by a minor presence of tin and iron), characteristic of the corroded patina. Among the non-metallic elements sulfur and chlorine, together with oxygen, have the higher concentration.

An area where the corrosion caused some damage aided the observation of the metallic substrate (Fig. 2B) with its microstructural features. Crystals which are visible on the Figure $2 \mathrm{~B}$ are well shaped and polygonal. Going up from the lower parts of the corroded stratifications, it is possible to see a few different layers of corrosion products. Chemical analyses show that the oxidized layer which is in direct contact with metal is richer in zinc but covered by the homogeneous layer of copper sulphide. An amount of phosphor has also been detected.

Furthermore, the chemical nature of the alloy has been confirmed by the compositional analysis of the uncovered metallic substrate, showing EDS spectra typical for brass with a low amount of tin.
Copper, zinc and tin are coming from the metallic substrate while iron, calcium, sulphur, phosphor and chlorine are obviously a contamination due to its deposition in soil. In order to quantitatively analyze and confirm this information, it was necessary to eliminate the patina and directly analyze the metal. An area where corrosive metallic substrates were slightly grinded is shown in Figure 2C. An EDXS standard analyses in areas 1 and 2 of Figure $2 \mathrm{C}$ confirmed the nature of the brass alloy with copper ( $82 \%$ at.), zinc ( $17 \%$ at.) and only $1 \%$ at. of tin. No lead was found in this sample.

The examination of the surface around the glass eye under the microscope revealed the presence of numerous flaking and pitting phenomena. Corrosive blooms and stratifications make the glass strongly corroded. The network of cracks covers the entire sample and the central part of the bead is heavily damaged by a deep fracture.

Chemical analyses show two dominated elements, copper and calcium. What is worth mentioning is that copper is present on the edge of the "eye" but not on the top of the bead. In contrast, calcium is measured all over the surface of the glass. High concentrations of these chemical elements are a consequence of glass corrosion (Fig. 1). In the more corroded areas, leaching (long contact with water) and the redistribution of soluble components (mainly alkaline) leads to the partial dissolution of the silicate network and the formation of micro-craters in the surface (Vilariques et al. 2010). Furthermore, the silica gel on the "eye" surface is enriched with iron, sulfur and phosphor. Those have been stratificated on the glass due to reactions with the surrounding environment (e.g. soil) (Greiner-Wronowa et al. 2007).

Moreover, the surface of the glass is also covered by inorganic material with a noticeable presence of arsenic and calcium, especially close to the borders where the junction with the metal part is situated. For this reason a small amount of this material was sampled to undergo a characterization by powder XRD (Fig. 1B) and a qualitative $\mathrm{XRF}$ analyses (Fig. 1B).

The analyses confirmed that the white deposit consisted of calcium and arsenic oxides mixed with a copper compound. Due the limited amount of powder, special equipment was used. XRF and XRD examinations of white corrosion products, as the one shown in the SEM micrograph in 
Figure 1A, spread all over the glass surface, showing enrichments in $\mathrm{Ca}$ and Arsenic. The calcium found is consistent with a glass corrosion mechanism, but arsenic does not come from the glass matrix or from the metal alloy, that the metal band is built of. It is well known that $\mathrm{Pb}$ can be used as a filler of broken or missing parts in $\mathrm{Cu}$ based objects (Gimeno 2008), acting as glue between the brass sheet and the brittle glass bead during the manufacture of the ring. Moreover, the lead can present a certain amount of arsenic as dopant. However, the experimental evidence shows the presence of arsenic but lead was not found in the samples. A possible explanation for this apparent inconsistent result can be attributed to the environmental degradation (for hundreds of years) than can provoke the dissolution of the $\mathrm{Pb}$, leading to a concentration of arsenic in the sample (Jokubonis 2003). It is anyway interesting to note how a deep insight into such historical objects can open perspectives of research and discussion.

The sample representing the combination of a glass element with copper was subjected to a battery of tests. The application of an acidic solution represented the aggressive environment and initiated the reaction of chlorides on the metal and glass (Fig. 3A). The copper band was dissolved in $0.1 \mathrm{M} \mathrm{HCl}$, and the resulting reaction formed a green crystalline corrosion on the entire surface of the glass and metal (Fig. 3B). Furthermore, the acid solution discolored and the reaction of the chloride ion with copper resulted in the precipitation of the product being crystallized over the entire surface of glass sensor. Weight loss suggests the presence of a dissolving phenomenon of the metal components in harsh environments, indicating broad changes in the glass-metal objects during degradation.
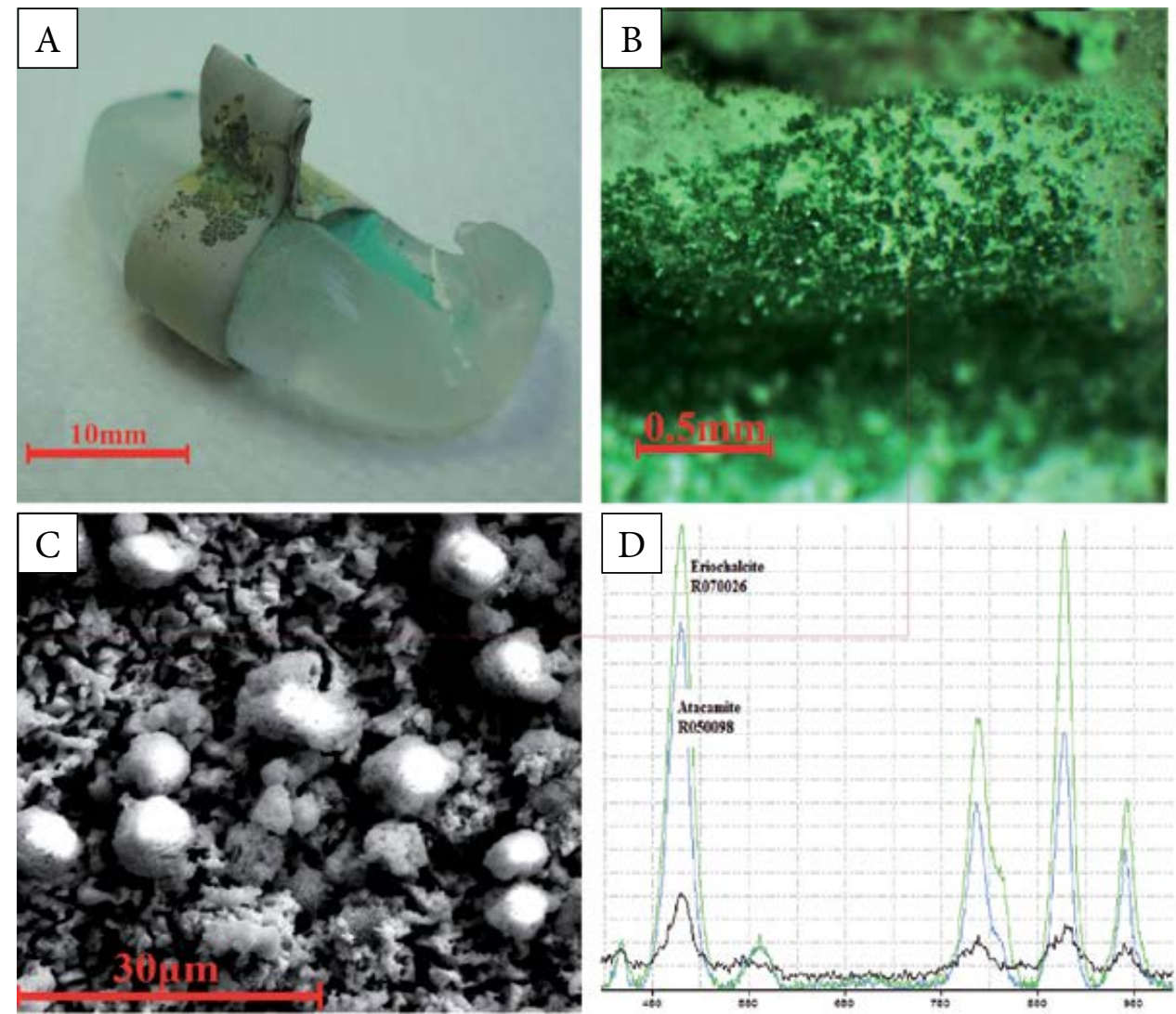

Fig. 3. Analysis of the glass sensor: A) observation after 2 weeks, sample immersed in $0.01 \mathrm{M} \mathrm{HCl}$; B) pictures of the samples after 20 weeks of induced corrosion of the samples in aqueous solutions, Wild Leica M8 stereoscope; C) the morphology of the surface, SEM/EDS analysis of the sample; D) Raman spectroscopy, Leica Renishow DMLM spectrometer. Line legend: blackexperimental sample, blue and green - spectra of individual minerals (from RRUFF ${ }^{\mathrm{rx}}$ Project). Numbers R050098 and R070026 are RRUFF ID (database of Raman spectra, X-ray diffraction and chemistry data for minerals) 
To examine the surface morphology and initially diagnose the chemical composition of the surface stratification, a SEM/ES analysis was performed. For the sample, thirteen measurements in total were made. Most of the analysis showed that the corrosion product is a compound of copper $(\mathrm{Cu})$, oxygen $(\mathrm{O})$ and chlorine $(\mathrm{Cl})$ (Fig. 3C). Also noted was the presence of carbon $(\mathrm{C})$, at a concentration of less than $7 \%$ by weight. It is very difficult to describe the shape of the crystallites. RS was analyzed to determine the phase composition.

For sample $\mathrm{D}$, only one measurement by $\mathrm{Ra}$ man spectroscopy (Leica Renishow DMLM) was performed on the green powder, because the corrosion product was on the whole surface of the sample and the solution. This apparatus uses two lasers at $514 \mathrm{~nm}$ and $785 \mathrm{~nm}$. A single beam spectrometer was used, with a camera connected to the confocal microscope and the imaging filter set to dispersive Raman imaging. The products have been identified as atacamite $-\mathrm{Cu}_{2} \mathrm{Cl}(\mathrm{OH})_{3}$ and eriochalcite $-\mathrm{CuCl}_{2} \cdot 2 \mathrm{H}_{2} \mathrm{O}$ (Fig. 3D). The first one belongs to the group of halides. It is perfectly pointed; the crystals are green, have a diamond shine and crystallized in a rhombic pattern. This mineral occurs in clusters, is needle-like and is clearly visible under the scanning electron microscope. This was shown to be an Eriochalcite crystallized ortho-rhombic system, a rare mineral which has a greenish-blue color.

The corrosive solutions of $0.01 \mathrm{M} \mathrm{HCl}$ were examined after some time of induced corrosion, using atomic emission spectroscopy with Inductively Coupled Plasma to diagnose the presence of metals and some non-metal elements. Attention was paid to the high concentration of calcium $(47.1 \mathrm{mg} / \mathrm{L})$. It can therefore be claimed that the alkaline cations in the glass structure are exchanged with chloride ions from the solution. This is confirmed by the measurable concentration of sodium and potassium. Structure-building elements of glass are detected in the solution at high concentrations $(\mathrm{K}=8.0 \mathrm{mg} / \mathrm{L}$ and $\mathrm{Na}=8.4 \mathrm{mg} / \mathrm{L})$. This demonstrates the glass-metal corrosion in acidic solutions. Metal ties are also dissolved at low $\mathrm{pH}$ levels which exhibits very high concentrations of copper $(\mathrm{Cu}=6400 \mathrm{mg} / \mathrm{L})$.

Previous studies were limited by the number of samples. The presented method allows the elucidation of the mechanism of corrosion of historical objects through the use of the so-called "Glass sensors" method. It is a great complement to traditional testing methods of historical objects.

\section{CONCLUSIONS}

This paper contributes to the investigations into the history, technology and degradation of middle age objects recently excavated under the Main Square in Kraków (Poland). The historical sample presented here belongs to a narrow group of metallic rings with mounted glass beads which were discovered in different ground layers in Kraków. All of the applied analyses were concentrated on the different corrosion stratifications which covered all parts of the ring, strongly damaging the glass bead as well as the metallic band and crown. The glass eye was mostly covered with silica gel and more advanced corrosion has been found nearby metallic sheets connected with glass bead, while the metal band was degraded by the corrosion processes completely. To recognize the chemical composition of the surface deposits, the glass and metal investigations were carried out separately.

Moreover, the study of medieval glass pearl rings allows quantification of the glass and metal alteration under natural conditions over periods of time of up to millennium. The analyses show that glass alteration is not only due to surface reactions caused by water penetration. Therefore, its degradation can be affected by differentiating surroundings (micro-climate) such as humidity, soil contamination, industry development or environment changes which, in fact, provoke different corrosion processes locally. Also, it is worth noting that the high level of jewelry manufacture (Olczak \& Jasiewiczowa 1963, Dekowna 1980, Eggert 2010 ) of the rings contribute to the knowledge of local history giving insights over the development of colonization in Krakow corresponding to the upper classes of the population dealing with the exchange of goods with foreign countries (WAWEL 1000-2000, Fuxi 2009).

Research conducted on the glass sensor can be considered as a real model for corrosion phenomena expansion, in this case, in an acidic environment (having in mind a acidic $\mathrm{pH}$ of the soil). Macroscopic and microscopic observations provided information about the corrosion's direction and the intensity of the processes. In an environment of hydrochloric acid $(0.01 \mathrm{M} \mathrm{HCl})$ applied 
to the glass sensor sample, it is clear that the band made of copper is not resistant and undergoes a process of dissolving, forming deposits on the surface of the glass, metal, and between these materials. Corrosion tends to start from the weakest materials and the formed corrosion products could induce the next stage of deterioration. The parameters for storing glass objects connected by two (or more) materials must be very well matched in order to avoid corrosion developing on one or two components. Usually the weakest began the deterioration process. Research shows that glass does not like to be kept in or near moisture and that metal is mostly sensitive to chlorides. Extensive tests allowed for the identification of the characteristics of the formed stratification.

The presented studies are a great evidence of why close collaboration between technologists and conservators is a necessity as possible to determinate a definitive condition of a historical object and apply the best methodology to ensure its conservation. Most importantly, materials such as these with historical value need to be protected in order to provide future generations with evidence of civilizations past.

The authors would like to gratefully acknowledge Prof P. Piccardo from University of Genova, for fruitful discussions and for providing the means to analyze (especially) the metal parts of the presented samples.

The research was financed by the AGH University of Science and Technology statutory grant no. 11.11.160.365/2014.

\section{REFERENCES}

Andrusieczko A., 1972. Technologia szkła: praca zbiorowa. Arkady, Warszawa.

Biezborodow M.A., 1956. Driewnierusskije stiekła i ognieupornyje izdielija. Kratkije Soobszczenija IIMK, 62, 79.

Dekówna M., 1980. Szkło w Europie wczesnośredniowiecznej. Zakład Narodowy im. Ossolińskich, Wrocław.

Eggert G., 2010. Corroding glass, corroding metals: survey of joint metal-glass corrosion products on historic objects. Corrosion Engineering, Science and Technology, 45, $5,414-419$.

Fuxi G., Brill R.H. \& Shouyun T., 2009. Ancient Glass Research along the Silk Road. World Scientific Publishing Company.
Gimeno D., Garcia-Valles M., Fernandez-Turiel J.L., Bazzocchi F., Aulinas M., Puges M., Tarozzi C., Riccardi M.P., Basso E., Fortina C., Mendera M. \& Messiga B., 2008. From Siena to Barcelona: Deciphering colour recipes of Na-rich Mediterranean stained glass windows at the XII-XIV century transition. Journal of Cultural Heritage, 9, 10-15.

Greiner-Wronowa E., 2005. Metoda sensorów szklanych $\mathrm{w}$ analizie przemian chemicznych korozji szkła. Świat Szkła, 5, 64-67.

Greiner-Wronowa E., 2010. Sensory szklane-metoda wczesnego monitorowania mikroklimatu w muzeum. Szkło i Ceramika, 3, 12-17.

Greiner-Wronowa E., Pusoska A. \& Piasecka J., 2007. Biały nalot na obiektach szklanych w gablotach muzealnych. Szkło i Ceramika, 1, 26-31.

Greiner-Wronowa E., Zabiegaj D. \& Piccardo P., 2013. Glass-metal objects from archaeological excavation: corrosion study. Applied Physics A, 113, 999-1008.

Jokubonis C., Wobrauschek P., Zamini S., Karwowski M., Trnka G. \& Stadler P., 2003. Results of quantitative analysis of Celtic glass artefacts by energy dispersive $\mathrm{X}$-ray fluorescence spectroscopy. Spectrochimica Acta Part B, 58, 627-633.

Kubiak WW. \& Gołaś J. (red.), 2005. Instrumentalne metody analizy chemicznej. Wydawnictwo Naukowe "Akapit”, Kraków.

Lierke R., 2009. Die nicht-geblasenen antiken Glasgefässe: ihre Herstellung von den Anfängen bis zu den Luxusgläsern der Römer. Deutsche Glastechnische Gesellschaft.

Olczak J., 1959. Proizwodstwo stieklanych pierstniej na slowanskoj territorii w srednije wieka. Sowietskaja Archeologija, 3, 81-83.

Olczak J., Jasiewiczowa E., 1963. Szklarstwo wczesnośredniowiecznego Wolina. Muzeum Pomorza Zachodniego, Szczecin.

Pfaender H.G., 1996. Schott Guide to Glass. $2^{\text {nd }}$ ed. Chapman $\&$ Hall, London.

Shelby J.E., 2005. Introduction to Glass Science and Technolo$g y .2^{\text {nd }}$ ed. The Royal Society of Chemistry, London.

Stawiarska T., 1984. Szkła z okresu wpływów rzymskich z północnej Polski. Studium technologiczne. Zakład Narodowy im. Ossolińskich, Wrocław.

Sulimirski T., 1943. Faience beads in the Polish Bronze Age. Man, 139, 124-125.

Theophilus, 1880. Teofila kapłana i zakonnika o sztukach rozmaitych ksiagg troje [księga 2: O pierścieniach]. Akademia Umiejętności, Kraków.

Vilarigues M., Redol P., Machado A., Rodrigues P.A., Alves L.C. \& Silva R.C., 2010. Corrosion of $15^{\text {th }}$ and early $16^{\text {th }}$ century stained glass from monastery of Batalha studied with external ion beam. Materials Characterization, 22, 40-52.

WAWEL 1000-2000, Biuletyn Informacyjny Biura Prasowego Kraków 2000, 32, 2000, [on-line:] http://www.krakow2000.pl/biuletyn/biuletyn_32.html.

Zabiegaj D., 2010. Zmiany korozyjne biżuterii szklanej z prac archeologicznych pod Rynkiem Głównym w Krakowie. AGH, Kraków [M.Sc. thesis]. 